\title{
BMJ Open Exploratory study on development challenges of maternal and child healthcare institutions in China: a qualitative study combining interviews and focus groups
}

Daisheng Tang, ${ }^{1}$ Meng $\mathrm{Li}^{2}$ Carolina Oi Lam Ung, ${ }^{2}$ Chengxiang Tang, ${ }^{3} \mathrm{Hao} \mathrm{Hu}^{\odot}$

To cite: Tang D, Li M, Ung COL, et al. Exploratory study on development challenges of maternal and child healthcare institutions in China: a qualitative study combining interviews and focus groups. BMJ Open 2019;9:e028789. doi:10.1136/ bmjopen-2018-028789

- Prepublication history for this paper is available online. To view these files, please visit the journal online (http://dx.doi org/10.1136/bmjopen-2018028789).

DT and ML are co-first authors.

Received 26 December 2018

Revised 14 May 2019

Accepted 30 May 2019

Check for updates

(c) Author(s) (or their employer(s)) 2019. Re-use permitted under CC BY-NC. No commercial re-use. See rights and permissions. Published by BMJ.

${ }^{1}$ School of Economics and Management, Beijing Jiaotong University, Beijing, China ${ }^{2}$ Institute of Chinese Medical Sciences, University of Macau, Taipa, Macao

${ }^{3}$ School of Public Administration, Guangzhou University,

Guangzhou, Guangdong, China

Correspondence to

Professor $\mathrm{HaO} \mathrm{Hu}$;

haohu@um.edu.mo;

polo.haohu@gmail.com

\section{ABSTRACT}

Objectives To manage the development of the maternal and child healthcare institution (MCHI) in China, it is important to understand the key challenges and the influencing factors for sustainable development of MCHIs. However, these areas have not been fully investigated previously. This qualitative study aims to systematically explore the perceived development challenges for MCHIs from the perspectives of MCHI staff and government officials.

Design Qualitative approaches, including focus group, semistructured interview and documentary analysis, were employed to identify development challenges encountered by the MCHIs in Chengdu city, China.

Participants Totally 16 medical staff of MCHIs and officials from local government.

Measures Participants' opinions about the development challenges for MCHI.

Results The study revealed the main development challenges for MCHls included: (1) incapability to provide differentiated medical service (including differentiated maternal and child health maintenance, integrative model of health maintenance and disease treatment, lack of innovation capability); (2) insufficient financial support; (3) shortage of gynaecologists and paediatricians; (4) insufficient facilities and medical equipment; (5) weakness in adopting information technology and (6) constraints of law and regulations.

Conclusions The study recommends that MCHI should take governance reform to promote healthcare innovation to ensure the sustainable development of MCHI. Publicprivate partnership needs to be considered for the sustainable development of MCHIs.

\section{INTRODUCTION}

Maternal and child healthcare is an important element of any national health systems especially for countries with large populations. Having the largest population in the world, China is always under increasing pressure of providing maternal and child healthcare. Since the establishment of the People's Republic of China, the Chinese government
Strengths and limitations of this study

- This study combined both qualitative interview method and focus groups to ensure data richness.

- Data were collected from individuals working at medical institutions and government departments to reflect diversified opinions about the development challenges of maternal and child healthcare institution (MCHI).

- Authoritative and instructive documents were also collected as a source of additional information about the background and development of MCHI.

- Future study needs to investigate the opinions of patient and their families about their opinions about $\mathrm{MCH}$.

- This study only focus on one region, which can be verified in other regions of China.

did not only mandate the development of the gynaecology and paediatric departments in general hospitals, it also established an independent maternal and child healthcare institution (MCHI) system through which most of the maternal and child health services were provided. ${ }^{1}$ According to the policy adopted by the central government, MCHIs at all levels are categorically public welfare institutions run by the government in the best interests of public health. They are the healthcare institutes that are charged with the responsibilities of promoting public health and providing basic medical services to women and children. The principles of MCHI are "Health maintenance as the centre, reproductive health as the goal, integration of health maintenance and clinical treatment, grass roots and prevention oriented'. MCHIs are required to work closely with other healthcare groups to ensure the needs at the grass roots level to promote disease prevention among women and children are 
met through health education, preventive healthcare and other public health services. The major objective of MCHI is 'to implement public health duties while at the same time carrying out basic medical services that are closely related to the health of women and children'. ${ }^{2}$ Until the end of 2015, there were 3078 MCHIs in China which employed 0.351 million employees, housed 0.195 million medical beds and provided treatment to 200 million people every year.

In recent years, the development of MCHIs has been facing with emerging problems. Specifically, as the popularity of national maternal and child health promotion grew, and the self-care awareness improved nationally, attention to the scope and quality of medical services provided to women and children increased. The parents asked for more advanced service such as children intelligence assessment, outpatient education and rehabilitation for children, maternal and child safety services, depression prevention and treatment for pregnant women and new mothers. ${ }^{34}$ Meanwhile, in 2016, the State Council of China officially loosened up the One Child Policy to allow a second child. The Second Child Policy has resulted in more women at high maternal age becoming pregnant and more women with multiple pregnancies contributing to the increased incidence of preterm infants and birth defects. ${ }^{5-7}$ In addition, there was also growing competition from both the public general hospitals and the private hospitals, challenging the survival of MCHIs. ${ }^{8-10}$

To overcome the challenges mentioned above, MCHIs began to explore new health service model. However, due to the lack of domestic guideline and mature model abroad, various problems raised during the process of health service innovation remained unsolved. For example, some MCHIs transformed into the general hospital model to provide services beyond the scope of maternal and child healthcare. ${ }^{11-14}$ Because clinical service could generate higher income, some MCHIs shifted their focus from health maintenance to clinical service downsizing the investment in the development of health maintenance services for mothers and children. ${ }^{1516}$ Competing interests also existed between different levels of MCHIs so that the growth of MCHIs at provisional and city level could also pose negative effect on the development of MCHIs at county level, preventing the provision of new healthcare services at country MCHIs. ${ }^{17}{ }^{18}$ Due to these development problems, scholars had argued there is a need to identify the key challenges and to clarify the internal interactions in order to better manage the development of MCHIs. However, full investigation of the challenges from the health system perspective has not been conducted so far. In particular, there was little research from the perspectives of the MCHI key stakeholders about the sustainability challenges facing MCHIs. ${ }^{19-22}$

\section{AIM}

This study aims to qualitatively explore the perceived development challenges for MCHIs from the view of the perspectives of MCHI staff and government officials. The Health System Dynamics Framework for dynamic analysis of the development challenges for MCHIs was used as it could allow a better understanding of health systems challenges by analysing the functioning of its key elements. ${ }^{23}$ It is expected that the findings of this study would provide in-depth information about the challenges faced by the MCHIs in China, which could be used to inform the design of future policy and inspire actions for sustainable development of MCHIs. It is also anticipated that the findings of this study will serve as reference for other countries when they plan for the development of maternal and child healthcare.

\section{METHOD \\ Study setting}

This study was conducted at Chengdu city, which is the provincial capital of Sichuan province. It has 15 administration districts, with a permanent resident population of 16.33 million in 2018 including 3.43 million women of childbearing age. The main issue of maternal and child health in this area was to meet the rising expectations for high-quality healthcare for mothers and children. As the economic and social centre of Southwest China, Chengdu city was selected to pilot the comprehensive reform of the medical and health system by the central government, including the reform of MCHI. In particular, the city was selected as one of the three cities to experiment national healthcare coverage for premature infants. Therefore, the findings from Chengdu city was expected to provide rich information about the development challenges of MCHIs in China.

\section{Research design}

Qualitative design was applied to investigate key informants' opinions in details about the development challenges of MCHIs based on their experiences and observations. Three data collection methods were adopted to ensure data saturation. First, focus group method was used to brainstorm the information about the development challenges for MCHI. Second, qualitative interview with key staff members of MCHI and related government officials was conducted to collect diversified but complementary data. The participants were invited because they were in the position to design the type of service MCHI could provide or to allocate resources for the development of MCHI. Third, documentary data were collected to obtain additional information that was not fully covered in the focus group and qualitative interview. All these three data collection methods collectively contributed to data saturation. The data saturation was finalised when no new theme emerged from data collection.

\section{Data collection}

The whole data collection process was coordinated by the Sichuan Population Association, which introduced the research team to the participants prior to the formal data 
Table 1 Participants in the focus group study

\begin{tabular}{|c|c|c|}
\hline Focus group 1 & Institution & Position \\
\hline \multicolumn{3}{|l|}{ Group 1} \\
\hline Participant 1 & $\begin{array}{l}\text { Maternal and child healthcare } \\
\text { institution }(\mathrm{MCHI}) \text { of district } \mathrm{A}\end{array}$ & Director \\
\hline Participant 2 & $\mathrm{MCHI}$ of $\operatorname{district} \mathrm{A}$ & Head of medical department \\
\hline Participant 3 & $\mathrm{MCHI}$ of $\operatorname{district} \mathrm{A}$ & Head of administration department \\
\hline Participant 5 & $\begin{array}{l}\text { Health and Family Planning Commission } \\
\text { of district A }\end{array}$ & Director \\
\hline \multicolumn{3}{|l|}{ Group 2} \\
\hline Participant 6 & $\mathrm{MCHI}$ of district $\mathrm{B}$ & Director \\
\hline Participant 10 & $\begin{array}{l}\text { Health and Family Planning Commission } \\
\text { of district B }\end{array}$ & Director \\
\hline
\end{tabular}

collection to obtain participants' trust. Two focus group discussions were organised at the MCHIs of District A and District B (see table 1). For each focus group discussion, the director, the head of medical department and the head of administration department of the district MCHI were invited. In addition, the key officers of the development and reform commission and the health and family planning commission at the district were also invited. The Development and Reform Commission is in charge of the main investment from the government while the Health and Family Planning Commission is in charge of medical regulations on MCHI. This participant composition ensures that the focus group discussion could allow exchange of opinions about development challenges of MCHI from the perspectives of both MCHI and the key government institutions. The focus group discussions were moderated by the first author who led the whole discussion process while the last author was responsible for taking field notes and recording the discussions. The two researchers were university professors with $\mathrm{PhD}$ degree and experience in focus group study. Written consent was obtained before the focus groups. Each focus group lasted for about 1.5 hours and was taped. Field notes were made during the focus group.

Qualitative interview was carried out after the focus group discussions to further clarify the key challenges identified by the focus groups. Six interviews were conducted with the key informants of MCHIs and the government from both city and district level (see table 2). An interview guide was developed and used to instruct the semistructured interview, which was mainly composed of three parts: (1) main policy support from the government; (2) main medical service development of MCHIs and (3) key development challenges faced by MCHIs. Interview was mostly focused on the third part while the first two parts provided background information. The interviews were

Table 2 In-depth interviews with key informants

\begin{tabular}{|c|c|c|}
\hline No & Institution & Position \\
\hline Participant 11 & $\begin{array}{l}\text { Development and Reform Commission of } \\
\text { Chengdu city }\end{array}$ & Department officer \\
\hline Participant 13 & $\mathrm{MCHI}$ of Chengdu city & $\begin{array}{l}\text { Deputy head of administration } \\
\text { department }\end{array}$ \\
\hline Participant 15 & $\mathrm{MCHI}$ of district $\mathrm{C}$ & $\begin{array}{l}\text { Deputy head of health maintenance } \\
\text { department }\end{array}$ \\
\hline Participant 16 & $\begin{array}{l}\text { Health and Family Planning Commission } \\
\text { of district C }\end{array}$ & Director \\
\hline
\end{tabular}


conducted by the first author and the fourth author with the assistance of one trained research assistant who was responsible for recording and taking notes. The three researchers were university professors with $\mathrm{PhD}$ degree and experience in qualitative interview study. Written consent was obtained before the interviews. Each interview lasted for 30-45 min and was taped. Field notes were made during the interview.

In addition to focus groups and key-informant interviews, authoritative and instructive documents were also collected. These documents included: (1) the annual reports and brochures of the four MCHIs visited; (2) the government reports of the Development and Reform Commission and the Health and Family Planning Commission at city and district levels; (3) the official policies and regulations about MCHIs from the central government. These documents were identified through the suggestions of the interviewees and based on a search in the policy database by the research team. These documents were used as a source of additional information about the background and development of MCHIs.

\section{Data analysis}

All the data collected from these three data collection methods were integrated for data analysis using a framework analysis method for qualitative data. ${ }^{24}$ First, the second and the last author studied all the data thoroughly to get familiar with the findings. Second, a thematic framework was developed with reference to the health system dynamics framework, which was composed of three components: service delivery, resources and governance. Third, the second and the final author did the coding separately. Fourth, the coding results were reviewed by the first author to ensure coding consistency. At last, the challenges identified were mapped to present and deepen the understanding about their relationship in the view of health system dynamics. The whole data analysis was supported by using NVivo V.11.0 software.

\section{Patient and public involvement}

No patient or public was directly involved in the design of this study. However, informed consent was obtained from all the participants in interview and focus group. Initial findings of this study have been shared with the participants. Findings of this study will be shared with a broader public audience and scientific communities through regional and national conferences.

\section{RESULTS}

Through qualitative analysis, six development challenges were identified. The first challenge 'challenge 1: Incapability to provide differentiated medical service' was related to service delivery. Four challenges were related to resources: 'Challenge 2: Lack of sufficient financing'; 'challenge 3: Shortage of gynaecologists and paediatricians'; 'challenge 4: Limited facilities and medical equipment' and 'challenge 5: Weakness in applying information technology'. The final challenge 'challenge 6: Constraints of laws and regulations' was related to governance.

\section{Challenge 1: incapability to provide differentiated medical service}

The participants generally thought that MCHIs needed to differentiate themselves from general hospitals by providing more medical services encompassing the continuum of maternal and child healthcare. However, current MHCIs had difficulty to provide such kind of differentiated medical services for three main reasons: (1) inadequate capability to provide differentiated maternal and child health maintenance; (2) difficulties in integrating clinical treatment and preventative healthcare and (3) lack of innovation (research) capability.

Inadequate capability to provide differentiated maternal and child health maintenance

The participants thought that, apart from the ordinary obstetrics and paediatrics, MCHIs needed to develop different medical services that were not provided by the general hospitals. However, the provision of advanced maternal and child health maintenance was lacking in the current MCHIs due to lack of certain capabilities. As one participant suggested:

The long-term direction of MCHIs should emphasize on the health maintenance through early education, reproductive health education, infertility education, birth defects intervention, etc. But our MCHIs do not have the capability to provide these services. (Participant 5, Director of Health and Family Planning Commission of District A )

Difficulties in integrating clinical treatment and health maintenance

The participants believed that it would be beneficial to the MCHIs if clinical treatment and health maintenance could be integrated in their services. Comparatively, the general hospitals mainly focused on the provision of clinical treatment but not health maintenance service. However, in reality, the MCHIs did not combine the two types of services as one participant explained:

Now (MCHI) emphasizes clinical but pays less attention to health maintenance. Clinical treatment leads to higher income. There is no job rotation between clinical physicians and health maintenance physicians. Some health maintenance physicians worked 'a lifetime' on health maintenance positions and needed to update their knowledge. (Participant 1, Director of MCHI of District A)

\section{Lack of innovation (research) capability}

To provide differentiated maternal and child healthcare services, MCHIs needed to develop some innovative knowledge and service by themselves. However, the participants generally thought that MCHIs did not have innovation capabilities because of the limits of manpower and funding resources. One participant noted: 
(MCHI) is short of research and development capabilities. There is no academic leader. (Participant 16, Director of Health and Family Planning Commission of District C)

\section{Challenge 2: lack of sufficient financing}

While all the participants thought that the government greatly increased the investment in MCHIs in previous years, participants from both the government and MCHIs agreed that MCHIs still had the problem with sufficient financing and there were two main reasons: (1) insufficient and unstable government funding; (2) price control on medical services by the government.

\section{Insufficient and unstable government funding}

Participants from MCHIs indicated that, for the regular operation cost of MCHIs, the government only provided a small amount of funding that was directly linked to physician quota controlled by government. Consequently, MCHIs had to rely on their medical services to cover most of the other costs. To make it worse, the government sometimes cancelled the funding that had been approved. The participants indicated that:

The input from the government is less. Most of hospital financing is obtained by (MCHIs) ourselves. (Participant 13, Deputy Head of Administration Department of MCHI of Chengdu City)

The investment promised by the district government was not delivered eventually. (Participant 16, Director of Health and Family Planning Commission of District C)

\section{Price control on medical services by the government}

Due to the nature of the public welfare institution, MCHIs were not in a position to set the service charges but had to follow the price standards controlled by the government, making it very difficult to generate additional income from the services provided in the same way the general hospital would do. One participant described:

As public medical institutions, MCHIs must follow the price standard set by the government and cannot charge patient more. The medical price standard by the state is very low. If you are responsible for all the investment, you cannot achieve self-financing. The general hospital can achieve self-investment, because they have many departments. The service scope of MCHIs is too small. It is difficult to achieve self-financing. (Participant 6, Director of MCHI of District B)

\section{Challenge 3: shortage of gynaecologists and paediatricians}

All the participants acknowledged that MCHIs generally experienced shortage of gynaecologists and paediatricians, which forced MCHIs to put in more financial resources to attract and keep gynaecologists and paediatricians. The external factor suggested was the decrease in the university education on gynaecology and paediatric affected the availability of qualified gynaecologists and paediatricians. Internally, participants indicated that the regulatory constraint on physician quota for each MCHI, less competitive compensation of MCHI and unpleasant working environment deteriorated their capabilities to attract new gynaecologists and paediatricians. One participant explained:

Both gynecologists and pediatricians are in shortage. Talents are difficult to be recruited for various reasons. First, the government set control on physician quota. Second, the salary is not as good as general hospitals and private hospitals. In our previous open recruitment, the selected doctors eventually chose to abandon our offers. Third, the working environment is bad. There were doctor-patient conflicts. (Participant 13, Deputy Head of Administration Department of MCHI of Chengdu City)

\section{Challenge 4: limited facilities and medical equipment}

Since all the facilities and medical equipment of MCHIs mainly depended on the government funding, the participants expressed their general concerns over the limitations of facilities and medical equipment. They thought, despite the government had invested a lot on constructing new buildings and purchasing new medical equipment for MCHIs since 2009 compared with the general hospitals in the same area, the facilities and medical equipment of MCHIs were still not complete and appropriately supplied. Two participants commented:

(MCHI's) facilities need improvement, which requires increasing investment. It needs to consider more function layout and process optimization when expanding facilities and building new facilities. (Participant 11, Department officer of Development and Reform Commission of Chengdu City)

Compared with general hospitals, we have less equipment. Our equipment is also less advanced than theirs. If some kind of examinations cannot be conducted in ours, patients will go to general hospitals. (Participant 6, Director of MCHI of District B)

\section{Challenge 5: weakness in applying information technology}

The participants generally agreed that MCHIs were experiencing challenges of applying information technology into their medical services. When the general hospitals had the capabilities to adopt electronic health record and customer relation management, MCHI did not have the same resources to invest on such kind of information systems. More importantly, the medical information system of each MCHI was isolated from those of the general hospitals and other MCHIs due to regulations of patient confidentiality. The isolated practice results in patients choosing the general hospitals or MCHIs at higher level over the ordinary MCHIs. Two participants mentioned:

Compared to the general hospitals, we are lagging behind in using information system for internal 
management and communicating with patients outside. Now the general hospitals had more advanced information systems. For example, they use APP on mobile phone, Wechat, short message of mobile phone, and website, etc., to manage their interactions with patients. But we do not have money to establish such system. (Participant 1, Director of MCHI of District A)

The information systems of the general hospitals and MCHIs are not open to each other. In addition, the information platforms of provincial, city and district (county) MCHIs are also isolated. Thus, the patients' medical information cannot be shared among each other. Participant 12, Deputy Head of Health Maintenance Department at MCHI of Chengdu City )

\section{Challenge 6: constraints of laws and regulations}

The participants indicated that recently some private hospitals started to provide service in the field of maternal and child healthcare. They competed with MCHIs with advanced equipment and attracted experienced gynaecologists and paediatricians by offering higher salaries. In order to combat these challenges, MCHIs needed more investment in addition to the government funding. However, current laws and regulations did not allow MCHIs to acquire investment from other sources. As indicated by one participant:

To develop and enlarge MCHI, we must encourage the investment of private capital from society to fix the gap caused by limited government investment. But there is no related policies or regulations in place to allow the collection and usage of private capital into MCHIs. (Participant 11, Department officer of Development and Reform Commission of Chengdu City)

\section{DISCUSSION}

The independent health system of MCHI in China had contributed to the promotion of health among women and children and the improvement in the quality of life for the Chinese population in the past decades. ${ }^{1}$ Nowadays, the Chinese patients are demanding healthcare services of higher quality. It is, therefore, crucial for MCHIs to innovate and deliver differentiated medical services to compete with the general hospitals. ${ }^{142526}$ However, this study found that MCHIs were facing multiple development challenges which are worth discussion in the following.

From the perspective of health system, the challenge of incapability to provide differentiated medical service of MCHI was largely due to resource constraints and governance limits. This study found that MCHIs faced the resource challenges of insufficient financing, shortage of gynaecologist and paediatricians, insufficient facilities and medical equipment, and weakness in adopting information technology. These resource challenges significantly affected MCHIs' ability to innovate and deliver differentiated medical services for pregnant women and children.

However, these resource challenges were rooted in the shortcomings of governance (constraints of laws and regulations). As public welfare institutions, MCHIs had to solely rely on government fiscal input to construct main facilities, buy main medical equipment, and pay basic salary of employees. Meanwhile, MCHIs had to follow the low service charge standard controlled by the government. In addition, MCHIs had to obey the management guidelines set by the government. For example, MCHI needs to follow the personnel quota rule of government and does not have rights to give financial award to its employees. Consequently, MCHIs did not have the autonomy to attract new financing input for the reform of the management system, resulting in the resource challenges mentioned above and the challenges of incapability in providing differentiated medical services eventually.

Thus, it is difficult to solve the resource challenges of MCHI without reforming governance (laws and regulations). Scholars had argued that government should invest more funding and allocate more medical staffs to MCHIs. ${ }^{1027-31}$ However, the government has its upper limit of fiscal input, which is especially difficult for the government in less developed areas. Therefore, it is impossible to just rely on government investment to improve MCHI's resource situation to promote its healthcare service. On the contrary, private medical institutions often charge high prices on medical services. Overpriced services can lead to unsustainable health maintenance services that are difficult to develop for women and children. ${ }^{32}$ Thus, government may allow the option of drawing private investment into MCHIs and introduce more flexible management mechanisms for more professional management. In other words, public-private partnership needs to be considered for the sustainable development of MCHIs and will benefit the medical service innovation of MCHIs.

Meanwhile, MCHIs could face various resource challenges even in the same area, as suggested by the interviewees from different MCHIs. Therefore, the service model of MCHIs may not be completely standardised and needs to be designed based on the local situations. The provision of services may be adjusted according to the total and composition of the regional population, the level of the regional economy, and other medical institutions that can provide similar services. For example, the proportion of migrant workers, the number of the second child, local availability of general hospitals and private specialty hospitals need to be evaluated to set the corresponding mode of service provision by MCHIs.

The findings of this study also have meaningful implications for the international maternal and child healthcare. In general, the experiences of MCHIs in China imply that specialised MCHIs can benefit countries with large population. The general hospitals may be reluctant to provide health maintenance services specific to woman and children. Through the establishment of specialised public welfare institutions, MCHIs can help promote the 
maternal and child healthcare innovation by integrating clinical treatment and health maintenance. For this, it is important to establish public and private partnership for MCHIs investment and operation that is consistent with domestic economic and population situation.

This study specifically targeted the development challenges of MCHIs in China, which were less reported in the current literature. Thus, the findings can enrich the field of maternal and child healthcare. However, it has several research limitations that can be addressed in future research. First, this study only collected the information from the staff members of MCHIs and related government officials. In order to gain a more comprehensive insight, future study needs to investigate the opinions of patient and their families, especially their need for MCHI service and their suggestions for reform and improvement of MCHI. Second, this study focused on Chengdu City in the Southwest region of China. The findings can be verified with future study in other areas of different social and economic context. Third, while public-private partnership is suggested for sustainable development of MCHI, uncertainties within public-private partnership remain. Future study is warranted to investigate the key governance structure and mechanisms that are specific to public-private partnership of MCHIs.

\section{CONCLUSIONS}

While the identity of the public medical institutions brings about a lot of government financial support to MCHIs in China, multiple challenges in MCHIs' sustainable development exist. The study recommends the reform of MCHI governance to promote healthcare innovation and to ensure sustainable development of MCHI.

Acknowledgements The authors gratefully acknowledge the support from the Sichuan Population Association.

Contributors DT and HH designed the research. DT, CT and HH collected the data. $\mathrm{DT}, \mathrm{ML}$ and $\mathrm{HH}$ analysed the data. ML, COLU and $\mathrm{HH}$ drafted the manuscript. All authors read and approved the final manuscript.

Funding The study was supported by grants from the Social Science Foundation of China (Project No. 14BRK027).

Competing interests None declared.

Patient consent for publication Not required.

Ethics approval This study was approved by the Ethics Committee of Beijing Jiaotong University (Project No. 14BRK027).

Provenance and peer review Not commissioned; externally peer reviewed.

Data sharing statement The qualitative data used to support the findings of this study are included within the article.

Open access This is an open access article distributed in accordance with the Creative Commons Attribution Non Commercial (CC BY-NC 4.0) license, which permits others to distribute, remix, adapt, build upon this work non-commercially, and license their derivative works on different terms, provided the original work is properly cited, appropriate credit is given, any changes made indicated, and the use is non-commercial. See: http://creativecommons.org/licenses/by-nc/4.0/.

\section{REFERENCES}

1. The people's Republic of China Ministry of health of maternal and child health care and community health department, Maternal and
Child Health Policy Research Project Results. 1. Beijing, China: Academic, 2006:34-8.

2. National health and family planning commission of the people's Republic of China. Ministry of Health on further strengthening the work of maternal and child health guidance. 2006. http://www.moh. gov.cn/mohbgt/pw10702/200804/18805.shtml (Accessed on 13 Mar 2017).

3. Tan G, Ye N, Huang S, et al. Analysis on the Development of New Children 's Health Care Program in Maternal and Child Health Care Institutions in Guangdong Province. Maternal and Child Health Care of China 2012;13:1932-3.

4. Chen Y. The SWOT Analysis and Countermeasure of Maternal and Child Health Care Institutions in Maternal and Child Health Service. China Medical Herald 2010;26:143-4.

5. Yang H, Yu Y, Liu K, et al. Analysis on the Influence of the Second Child Policy on the Incidence and Outcome of Preterm Infants in Beijing. Maternal and Child Health Care of China 2017;01:10-12.

6. Li S. Study on Reconstruction and Design of New Maternal and Child Health Care Institutions. Chongqing, China: Master thesis, Chongqing university, 2016.

7. Gao Y. How Maternal and Child Health Institutions Respond to Fertility Policy Adjustment[n] china Population newspaper. 2016.

8. Pan X. On the Construction of Core Competence in the Development of Maternal and Child Health Care Institutions. Chinese Primary Health Care 2010;01:49-50.

9. Zhou L, Yang Z, Zhou C, et al. On the Core Competence of Maternal and Child Health Care Institutions. Maternal and Child Health Care of China 2008;05:588-90.

10. Wang $Y$, Jiang $Q$. The dilemma that maternity and child health care sectors of are confronted with and strategies to help these sectors break away from the dilemma. Chinese Primary Health Care 2003;02:60-2.

11. Wellhoner M, Lee AC, Deutsch K, et al. Maternal and child health in yushu, qinghai province, china. Int J Equity Health 2011;10:42.

12. Zhang WF, $\mathrm{Xu} Y \mathrm{YH}$, Yang RL, et al. Indicators of child health, service utilization and mortality in Zhejiang Province of China, 1998-2011. PLoS One 2013;8:e62854.

13. Cheng F. Study on the management of maternal and child health care institutions in china. Master thesis, Dalian Maritime University, Dalian, China 2014.

14. Hu Z. Comparative study on the model of maternity and child care institutions. Journal of Public Health and Preventive Medicine 2012;06:1-5.

15. Zheng $\mathrm{H}$. Reflections on the Working Mode of Maternal and Child Health Care Institutions Maternal and Child Health Care of China 2010;35:5165-6.

16. Fan Y, Pei L. Reflections on the Transformation of Maternal and Child Health Care Institutions in China. Maternal and Child Health Care of China 2007;24:3334-6.

17. Nie Y, Wang C, Luo R, et al. Analysis on current situation of doing their duty among maternal \& child healthcare centers in 2008. Maternal and Child Health Care of China 2011;14:2085-7.

18. Wang $\mathrm{X}$, Zhou $\mathrm{H}$, Wang $\mathrm{Y}$, et al. constructing status of service system in different levels of maternal and child health institutions in Yunnan province. Chinese Journal of Woman and Child Health Research 2008;01:41-4.

19. Ren Z, Song P, Theodoratou E, et al. China's human resources for maternal and child health: a national sampling survey. BMC Health Serv Res 2015;15:561-71.

20. Zhang $\mathrm{Y}$, Chen $\mathrm{L}$, van Velthoven $\mathrm{MH}$, et al. mHealth Series: Measuring maternal newborn and child health coverage by text messaging - a county-level model for China. J Glob Health 2013;3:020402.

21. Nie $\mathrm{Y}$, Huang $A$, Luo $R$, et al. Analysis on resource allocation status of three - level maternity and child care institutions in China in 2008. Maternal and Child Health Care of China 2011;11:1607-9.

22. Zhang L, Zhao Y. Current Situation and Suggestions of Maternal and Child Health Care Service in Chinese Community. Maternal and Child Health Care of China 2007;12:1586-9.

23. Olmen JV, Criel B, Bhojani U, et al. The Health System Dynamics Framework: The introduction of an analytical model for health system analysis and its application to two case-studies. Health, Culture and Society 2012;2:1-21.

24. Gale NK, Heath G, Cameron E, et al. Using the framework method for the analysis of qualitative data in multi-disciplinary health research. BMC Med Res Methodol 2013;13:117-25.

25. Jiang W, Xie D. Study on performance comprehensive evaluation in maternal and child health care hospitals at city level in Hunan province. Maternal and Child Health Care of China 2015;33:5731-4. 
26. Han W. Research on Human Resource Allocation and Management in Maternal and Child Health Care Institutions. Oriental Enterprise Culture 2015;21:94.

27. Huang A, Zhang L, Luo R, et al. Progress of Monitoring of Maternal and Child Health Care Institutions in 2004-2008. Chinese Journal of Women and Children Health 2010;1:7-9.

28. Du Y, Liu Y, Ti H, et al. Optimization and integration of maternal and child health care institutions and family planning organizations: progress, problems, and countermeasures. Maternal and Child Health Care of China 2016;1:1-4.

29. Wen $Y$, Fan S, Wang $H$. Research on the existing problems and countermeasures in the development process of grassroots maternal and child health care institutions in Sichuan province. Maternal and Child Health Care of China 2016;17:3431-4.

30. Jia W, Zhu L. Reflections on the Orientation and Development of Municipal Maternal and Child Health Care Institutions. Maternal and Child Health Care of China 2007:19:2603-5.

31. Huang J, Qiu L, Yang H, et al. Analysis on the Trend of Service and Development Ability of Maternal and Child Health Care Institutions in Shanxi Province from 2008 to 2012. Maternal and Child Health Care of China 2013;29:4772-3.

32. Wang J, Luo R, Qi Y, et al. cost accounting for population health service items of $\mathrm{MCH}$ institutions. Chinese Journal of Woman and Child Health Research 2008;5:462-5. 